\title{
A Cross-linguistic Study of Prepositions in Persian and English: The Effect of Transfer
}

\author{
Masoud Mahmoodzadeh \\ Sheikhbahaee University, Isfahan, Iran \\ Email: masoudmahmoodzadeh@yahoo.com
}

\begin{abstract}
The present paper is a contrastive study which attempts to investigate the errors made by Iranian EFL learners due to the cross-linguistic influence between their L1/SL and L2/TL language (i.e. Persian \& English respectively). To meet the goals of the study, an error analysis was conducted to examine the status of different types of errors of prepositions made due to the transitional constraints between Persian and English languages. To this end, a translation task was developed by the present researcher. The translation task aimed at identifying the interlingual preposition errors caused by the process of transfer between the target language (English) and the source language (Persian). The translation task was then given to 53 adult EFL learners at intermediate level to translate the sentences from Persian into English during the allotted time. After collecting and analyzing the data, the corollaries of the study indicated that the Iranian EFL learners under investigation were faced with the errors related to the wrong and redundant use of prepositions more frequently as compared with the errors related to the omission of prepositions in $L 2$ while translating from Persian into English. The findings might make a significant contribution to the preparation of corpus of preposition errors in Iranian EFL learners discourse and thus inform Iranian ELT practitioners and teachers of the cross-linguistic areas of difficulties concerning the acquisition of second language prepositions.
\end{abstract}

Index Terms-Contrastive Analysis, cross-linguistic transfer, language prepositions, EFL learners

\section{INTRODUCTION}

In the middle of the twentieth century, the importance of the cross-linguistic influence of two languages in contrast was called into attention and soon came into vogue in the circle of applied linguistics through the influence of the thought-provoking inception of Contrastive linguistics $(C L)$ as a new well-founded disciple. Following the adoption of the premises of CL, researchers and practitioners were endowed with numerous pedagogical insights and implications because the reported findings were essentials of language teaching in the heyday of structural linguistics, behavioristic psychology, and pattern practice language teaching methodologies such as audiolingual method (Brown, 2000, James, 1980).

As Krzeszowski (1990) discusses, early contrastive studies, however, mainly revolved around the assumption that when a learner learns a new language, he/she usually focuses his attention on discrepancies and if he/she discovers some similarities, he/she is amused and surprised since making such similarities explicit for the learner may facilitate the process of second language learning. In addition, originally all contrastive studies were pedagogically motivated and oriented; however, some distinctions have been drawn between "theoretical" and "applied" contrastive studies. In this respect, Krzeszowski likewise contends that applied contrastive studies are distinct from theoretical contrastive studies; the former studies, as part of applied linguistics, "must depend not only on theoretical ,descriptive, and comparative linguistics but also on other disciplines relevant to teaching including psycholinguistics, sociolinguistics, dialects, and psychology of learning" (pp. 10-11).

However, the applied contrastive linguistics can practically and pedagogically be realized but considered useful by syllabus designers, practitioners only to the extent to which appropriate use can be made of it in the given teaching milieu (Krzeszowski ,1990). In the light of this assumption, the present study intends to investigate the errors made due to the cross-linguistic influence between the L1/SL and L2/TL language (i.e. Persian \& English). To do so, an error analysis has been conducted to examine the status of different types of preposition errors made on account of the transitional constraints between the SL (Persian) and the (TL) English. It is also worth noting that only a few studies have attempted to explore the cross-linguistc influence of English and Persian prepositions on second language learning; therefore, this study might contribute to enrich the body of cross-linguistic knowledge vis-à-vis English prepositions versus Persian prepositions. Furthermore, the significance of the study is to manifest some findings that may help teachers to present teaching materials more appropriately and also assist syllabus designers and material developers in selecting and grading of ELT materials.

\section{RESEARCH QUESTIONS}

To serve the aims of the study, the following questions were raised:

1. To what extent do Iranian EFL learners make the prepositional errors in the translation task? 
2. What types of errors in use of prepositions (omission of prepositions, redundant or wrong use of prepositions) are more likely to be made by Iranian EFL learners via the translation task?

\section{LITERATURE REVIEW}

\section{A. The Historical Perspective of Contrastive Analysis (CA)}

By definition, Richards and Schmidt (2002) concisely state that contrastive analysis is based on the following three maxims: "a) the main difficulties in learning a new language are caused by interference from L1; b) the difficulties can be predicted by CA; c) teaching materials can make use of CA to reduce the effects of interference" (p.119). In another sense, James (1980) advocates the attitude that CA is a hybrid which relies very strongly on psychology and linguistics because learning involves psychological processes. He likewise assigns CA to a science of applied linguistics for two reasons: firstly, because it is different from "pure linguistics" in drawing on other scientific disciplines; and secondly, because linguistics is the science upon which it draws most heavily. In essence, as Stern (1983) asserts, CA was not a new teaching method; but it was a form of language description applicable to language teachers, materials and curriculum developers, and test designers.

In the same vein, Keshavarz (1994) discusses that during the 1950s and 1960s, CA was considered as the ultimate panacea for language teaching problems: predicting and solving learners' errors and difficulties. Based on the assumption that second/foreign language learners tend to transfer the formal features of their L1 to their L2 utterances, structural linguists set out to identify areas of difficulty for second language and produce appropriate teaching materials to overcome these linguistic obstacles. In effect, on the one hand, the task of a contrastive analyst was to pinpoint the items in learner's L1 which are in line with the similar items in learner's L2 (positive transfer) so as to facilitate language learning process. On the other hand, the contrastive analyst identified the areas of asymmetry between the learner's L1 and L2 (negative transfer) and predicted the areas of learning difficulties and thus avoided the probable linguistic phenomenon of interference which was believed to seriously hinder the process of second language learning.

To compare and contrast the various linguistic items practically, an offshoot of this discipline emerged called Contrastive Analysis Hypothesis (CAH) which gained significant kudos in the domain of applied linguistics. To elaborate on this hypothesis, Brown (2000) argues that

...the $\mathrm{CAH}$ claims that the principal barrier to second language acquisition is that the interference of the first language system with the second language system, and that a scientific, structural analysis of the two languages in question would yield a taxonomy of linguistic contrast between them which in turn would enable the linguist to predict the difficulties a learner encounters (p. 208).

For all the prevailing prosperous CA-based findings in the 1960s, the ascribed predictive axiom of CAH was severely criticized and called into question in the 1970s (e.g. Corder, 1973; Oller \& Ziahosseiny, 1970; Whitman \& Jacson, 1972; Wode, 1967). Hence, Wardhaugh (1970) termed the early version of CAH strong version and called for an alternative version of the early $\mathrm{CAH}$ called weak version in which a priori prediction of certain linguistic items across languages was not claimed and the influence of learner's L1 system was emphasized instead of the predictive value of the learner's L1 system. According to Brown (2000), today the weak version of CAH can still be viewed under the general label cross-linguistic influence (CLI) (see Kellerman \& Smith, 1986) which realizes the influence of the learner's native language as prior knowledge or experience on second language learning and teaching.

\section{B. The Emergence of Error Analysis (EA) in Applied Linguistics}

In the late 1960s, applied linguistics began to witness a new wave of research culminating in the emergence of the new concept of error analysis $(E A)$. In fact, EA was introduced as an alternative to CA in which the understanding of the nature of errors was revisited. That is to say, errors were not treated any longer as debilitative and embarrassing faults. But instead, they could provide researchers with feedback to identify learning strategies because errors reflect the competence of learners. In this sense, errors were not only attributed to the learner's L1 (i.e. negative transfer/interference) but also to the learner's L2 system; therefore, intralingual transfer was proposed accounting for the unexplained errors not caused by interlingual transfer, namely, interference. To expound on the discrepancy between these two types of transfers, it is generally argued that unlike interlingual errors, intralingual errors were solely associated with the learner's L2 (Brown, 2000). Further, EA could give important additional source of information for the selection of items to be incorporated into syllabuses. In principle, EA thus paved the way for teachers to ameliorate their teaching methodology and maintain a state of alert in terms of what parts of their syllabus have been inadequately learned or taught and need further attention (see, for example, Corder, 1981).

According to Corder (1973), error analysis has two objectives: one theoretical and another applied. The theoretical objective serves to check the validity of theories, namely the psycholinguistic theory of transfer. The applied objective concerns pedagogical purposes. When errors are analyzed, the nature of difficulties and problems faced by L2 learners is identified which helps teachers to modify their way of teaching and checking their teaching materials. In terms of the proposed EA models, there are two important models; first, Corder (1974) identified a model for error analysis including three stages: data collection, description and explanation. Following this model, two decades later Gass and Selinker (1994) then complemented the early model and identified 6 steps followed in conducting an error analysis, 
namely, collecting data, identifying errors, classifying errors, quantifying errors, analyzing source of error, and remediating for errors.

However, EA was later carried out within the learner interlanguage system (Selinker, 1972) due to the fact the second language learner develop a dynamic and approximate system (Nemser, 1971) which is in all likelihood unique itself along with the learner's idiosyncratic dialects (Corder, 1971) which are unique to a particular individual learner. In essence, the active role of learners is taken into account in this way while the learner's strategy of avoidance could also be explained and examined. In other words, error analysis emphasizes the significance of errors in the learner's interlanguage system but the absence or present of errors does not necessarily reflect native-like competence (Brown, 2000). According to Corder (1974, p. 27), the results of error analysis "can help teachers to adapt themselves to the learner's needs rather than impose upon him their (the teachers') preconceptions of how he ought to learn and when he ought to learn". As Erdogan (2005) discusses, “error analysis deals with the learners' performance in terms of the cognitive processes they make use of in recognizing or coding the input they receive from the target language. Therefore, a primary focus of error analysis is on the evidence that learners' errors provide an understanding of the underlying process of second language acquisition" (p. 263).

\section{The Introduction of Conceptually-based Contrastive Analysis}

Granted the fact that conceptual errors have increasingly been reported in learners discourse and interlanguage systems (Danesi, 2000, Russo, 1997), Danesi (2003) attempted to revitalize CA based on a conceptually-oriented model and introduced a revamped CA called conceptually-based CA. In this recently developed kind of CA, the emphasis is given to the underlying conceptual structures reflected in language grammar, vocabulary, prosody, and so forth. According to Danesi (2003), within the crux of this contemporary view of CA lies our conceptual systems which are "culturally transmitted to us, through language, through our use and understanding of the language, and through other representational activities to which we are composed in a culture"(p. 91).

Over the last decades, most debates and attempts in Second Language Teaching (SLT) have been virtually directed towards the enhancement of linguistic and communicative competences whereas the conceptual competence has been taken for granted (see Talebinezhad, 2007; Talebinezhad \& Hashemian, 2006). In effect, Danesi (2003) believes that the lack of conceptual confidence in language learners is one of the most crucial factors accounting for vexing challenges in the circle of second language pedagogy which have ultimately led to the emergence of a kind of pedagogical quandary over the last decades called SLT Dilemma (see also Mahmoodzadeh, 2011 for a critical discussion on the theoretical trends towards this dilemma). Given the belief that conceptual competence is teachable and can be imparted in the classroom, Danesi (2003) defines conceptual competence "as the ability of language learner to verbalize concepts so as to construct messages that have a culturally-appropriate structure, no matter what suitable syntactic or morphological form they assume" (p. 75).

In this regard, it should be noted that conceptually-based CA is directly related to the notions of conceptual competence and conceptual fluency. Unlike, Verbal fluency which is defined as the grammatical and communicative abilities of an L2 learner for producing discourse, conceptual fluency refers to the ability to use and comprehend the conceptual concepts of a given language. Thus, to be conceptually fluent in a language is to know how that language reflects or encodes its concepts on the basis of metaphorical structuring (Danesi, 2003; Talebinezhad \& Hashemian, 2006).

In a conceptually-based CA, following the identification of the main domains that allow native speakers to deliver this concept in discourse, language teachers, textbook designers, and syllabus designers can resort to the achieved results of the conceptual analysis to become aware of the areas of interconceptual interference and also intraconceptual interference (Danesi, 2003). Furthermore, Danesi claims that conceptual syllabuses "can be integrated with grammatical and communicative syllabuses but the core premises of the course and textbooks should revolve around concepts such as time, love, health, and etc." (p. 101).

\section{The Cross-linguistic Influence of Prepositions}

Prepositions as an important area of English grammar are generally found difficult by EFL/ESL learners. According to Pittman (1966), among those who teach or learn English language, prepositions have earned a reputation for difficulty if not downright unpredictability. In a similar vein, Takahaski (1969) argues that the correct usage of prepositions is the greatest problem for learners of English. By definition, a preposition expresses a relationship between entities: it indicates a relationship in space (between one object and another), and/or a relationship in time (between events). In addition to other relationships such as instrument and cause (Quirk et. al., 1993), prepositions can be used with different parts of speech of the same root word.

Prepositions can be classified according to their form, function and meaning. Concerning form, prepositions can be simple (one-word preposition), or complex (also called two- word, three-word, or compound prepositions). Simple prepositions are closed class. That is, we can not invent new single word prepositions. However, complex prepositions are open class because new combinations could be invented (Grubic, 2004, as cited in Asma, 2010). In English, there are, however, approximately seventy simple prepositions. The most frequently used are: at, by for, from, in, of, on, to and with. With regard to prepositional phrases, Quirk et al. (1993) view that a prepositional phrase is made of a 
preposition followed by a prepositional complement which is a noun phrase (e.g. at the bus stop) or a WH-clause (e.g. from what he said) or V-ing clause (e.g. by signing a peace treaty) (cited in Asma, 2010).

However, several studies (e.g. Jimenez Catalan, 1996) have been conducted thus far exploring the cross-linguistic transfer of English prepositions across different languages. For example, in Arabic language, Hamdallah and Tushyeh (1993) and also Hasan and Abdullah (2009) have examined the cross-linguistic influence of prepositions across English and Arabic languages. Likewise, Asma (2010) has recently investigated the reality of the phenomenon of simple prepositions transfer from Standard Arabic into English by Algerian EFL learners. Through a designed test consisting of twenty sentences, she concluded that Standard Arabic is not the only source of transfer for Algerian learners since they transfer from French and Algerian Arabic as well. Thus, Algerian learners rely on Standard Arabic, in addition to French and Algerian Arabic prepositional knowledge in order to acquire English language prepositions.

However, only a few studies have been carried out so far investigating the use of English prepositions among EFL learners in the Iranian context. For example, Delshad (1980) conducted a contrastive study of English and Persian prepositions and found that Iranian EFL/ESL students have difficulty in the use of English prepositions. According to Delshad, Iranian EFL learners seemingly tend to misuse or omit English prepositions (as cited in Jafarpour \& Koosha, 2006). Likewise, in an endeavor to determine the extent to which Iranian EFL learners' knowledge of collocation of prepositions is affected by their L1, Jafarpour and Koosha (2006) conducted a study in which the errors of the collocations of prepositions turned to yield the significance of Iranian EFL learners' L1 transfer. That is, Iranian EFL learners tend to carry over their L1 collocational prepositions to their L2 production.

\section{Methodology}

\section{A. Participants}

In this article, the present researcher considered Iranian EFL adults learners at intermediate level as subjects of the study. The number of subjects was 53; thirty were male and twenty-three were female learners studying English at a Foreign Language Institute in Mashhad, Iran. The criterion used to select the subjects in question was a placement tests which had already been administered to measure their language proficiency. The test was a locally-developed placement test designed by the institute's experts.

\section{B. Instruments}

Since some language speakers are more reflective and reserved, using only what they are sure they know in their attempting to speak the target language cannot help us to compare optimally the errors made by various speakers. In fact, if learners are not obliged to use any target language structures which they are not certain about, they may avoid the problematic target language structures accordingly. To consider cautiously the hidden effects of this learning strategy, translation can be regarded as the best basis of comparison of languages (James, 1980). In this sense, the translation technique as an elicited procedure has several advantages. First, it forces the subjects to attempt to produce the structures under investigation. Secondly, it assures the researcher that the subjects understand the semantics of the structure he is required to produce (Keshavarz, 1994).

Thus, the instrument applied to collect data in this study was to employ a translation task developed by the researcher. Much attention was, however, given to the development of a translation task which aims at identifying the interlingual preposition errors caused by the process of transfer between the target language (English) and the source language (Persian). Meanwhile, much attempt was made to suit the translation task to the participants ' current level by reducing the lexical difficulty of the translation items. The developed translation task includes 15 problematic sentences in Persian selected based on the most cross-linguistically challenging prepositions observed by the researcher in Iranian EFL classrooms throughout his teaching experience. The selected sample of prepositions includes both simple prepositions and prepositional phrases. These chosen sentences were felt to cause some cross-linguistic errors in the use of propositions for Persian-speaking Iranian EFL learners. The translation task (see Appendix) consists of:

a) Three sentences for absence of propositions in L1 (No. 2, 3, 6, 14, 15)

b) Three sentences for redundant prepositions in L1 (No. 1, 5, 7, 9, 11)

c) Three sentences for different equivalent propositions in L1 (No. 4, 8, 10, 12, 13).

\section{Procedures}

To evaluate systematically the type and the extent of the propositional errors committed by EFL learners in Iran due to the cross-linguistic influence between the two languages, the developed translation task was given to the involved participants to render the sentences within the allotted time. In order to collect the relevant and useful data to meet the purpose of the study, first, the participants were told that the translation task was not an exam or a test having any effect on their class performance; secondly, they were allowed to do the task in only 10 minutes, that is, less than one minute per sentence. In doing so, the participants were forced to write their first immediate response and as such, they would spontaneously render the sentences and the factor of timing could be considered in this way. To collect the necessary data, the translation task was then given to the participants.

D. Data Analysis 
After calculating the data, as was expected, the responses that the subjects gave to the translation task were of three kinds: wrong or inappropriate equivalence; omitted prepositions, and redundant prepositions. To categorize the obtained data clearly, the results of frequency of translation errors in terms of the use of prepositions in the translation task are tabulated and shown in the following:

TABLE 1.

FREQUENCY OF DIFFERENT TYPES OF TRANSLATION ERRORS IN TERMS OF THE USE OF PREPOSITIONS IN THE TRANSLATION TASK

\begin{tabular}{|l|l|l|}
\hline Error Type & Frequency \% & Questionnaire Items \\
\hline Omission & $9.2 \%$ & No. $2,3,6,14,15$ \\
\hline Redundancy & $46.4 \%$ & No. $1,5,7,9,11$ \\
\hline Wrong Use & $52 \%$ & No. $4,8,10,12,13$ \\
\hline
\end{tabular}

TABLE 2.

DESCRIPTIVE STATISTICS FOR ERRORS IN USE OF PREPOSITIONS (HIGHLIGHTED IN RED) RELATED TO INDIVIDUAL ITEMS OF TRANSLATION TASK

\begin{tabular}{|l|l|l|l|}
\hline No. & Preposition Errors & Type of Errors & Frequency \% \\
\hline 1 & twice in a week & redundancy & 71 \\
\hline 2 & rest --- 3o minuets & omission & 7 \\
\hline 3 & $---6: 30$ a.m. & omission & 4 \\
\hline 4 & afraid from & wrong use & 53 \\
\hline 5 & asked from & redundancy & 18 \\
\hline 6 & -- Fridays & omission & 11 \\
\hline 7 & enjoyed from & redundancy & 56 \\
\hline 8 & different with & wrong use & 32 \\
\hline 9 & --- the next day & redundancy & 42 \\
\hline 10 & from TV & wrong use & 22 \\
\hline 11 & went to home & redundancy & 45 \\
\hline 12 & depends to & wrong use & 74 \\
\hline 13 & died from & wrong use & 79 \\
\hline 14 & --- weekends & omission & 20 \\
\hline 15 & worked --- two hours & omission & 4 \\
\hline
\end{tabular}

* Note: The represented statistical figures have been rounded off.

\section{RESUlTS AND DisCUSSION}

As related before, the purpose of this study is to figure out what types of errors in use of prepositions (omission, redundant or wrong use) are more or less likely to be committed by Iranian EFL learners through a translation task. In this respect, Table 1 shows that the subjects under study have made errors related to wrong use and redundancy of prepositions more frequently as compared with errors related to the omission of prepositions in L2 while translating from Persian into English.

In particular, $52 \%$ and $46.4 \%$ of the subjects made errors belonging to wrong use and redundant prepositions respectively in the translation task, whereas only $9.2 \%$ of the subjects had difficulty rendering the prepositions which are omitted in English language. To sum up, it can be implied that Iranian EFL learners are more likely to suffer from some difficulties in producing (i.e. translating, speaking, \& writing) English prepositions which are either redundant or wrong in Persian language. More particularly, for instance, among the prepositional phrases listed in Table 2, the redundant preposition in phrases such as "twice in a week" (71\%) and the wrong use of prepositions in phrases like "die from" (79\%) or "depend to" (74\%) were among the most frequent errors made via the translation task. In contrast, omission error of prepositions in phrases such as "--- 6: 30 a.m." (4\%) and " worked --- two hours" were among the least frequent errors made by the subjects of the study.

The pedagogical implications of this study can in part inform Iranian syllabus designers and material developers to consider the level of cross-linguistic difficulty in use of prepositions in selection and grading of materials such as the unit organization of course books. Likewise, another implication is to enlighten the knowledge and understanding of Iranian language teachers as how to provide learners with more efficient corrective feedback while treating preposition errors made in the classroom. In an endeavor to diminish the difficulty acquiring second language prepositions, it is suggested that language teachers and practitioners delve deeper into the issue of prepositional corrective feedback and attempt to deliver corrective feedback considering the cross-linguistic error gravity of the given prepositions for production. Finally, the findings of the study may enrich the corpus of preposition errors made by Iranian EFL learners. However, one limitation of the study is that the small sample size restricts the generalization of the achieved findings. Thus, there is a need for further research to cross-validate finding from the present study to a different and larger sample. In addition, Iran is not the only Persian speaking country in Asia and other language varieties of Persian are spoken elsewhere so that further similar cross-linguistic studies are called for the investigation of language prepositions among other Persian-speaking Asian EFL learners. 


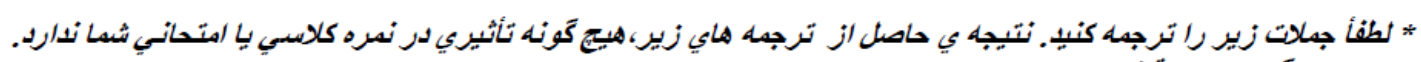

* Please translate the following sentences. The result of your translation has no effect on your class performance or your final examination grade. Allotted time: 10 minutes

* Correct equivalents of the above Persian sentences translated into English.

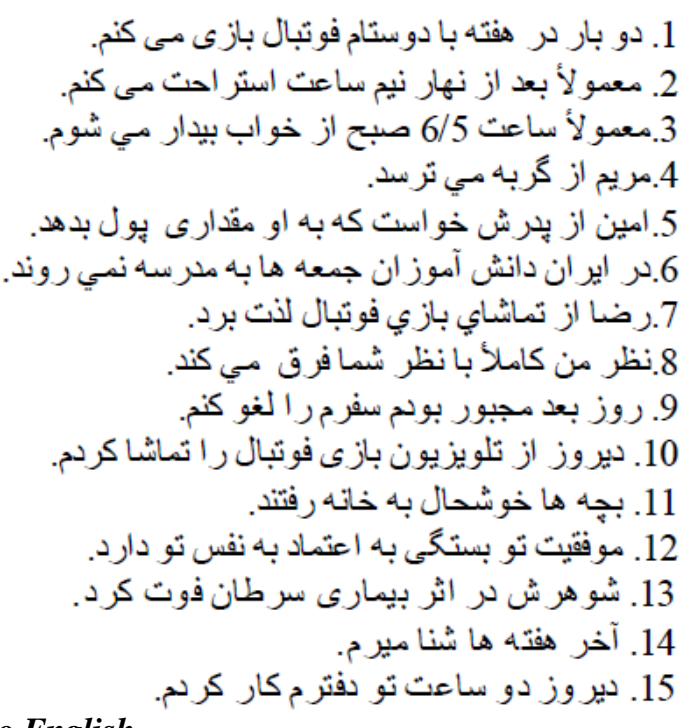

1. I play football with my friends twice a week.

2. I usually rest for 30 minutes after lunch.

3. I usually wake up at 6:30 a.m.

4. Maryam is afraid of cats.

5. Amin asked his father to give him some money.

6. On Fridays, students do not go to school in Iran.

7. Reza enjoyed watching the football game.

8. My idea is totally different from your idea.

9. In the next day, I had to cancel my trip.

10. I watched the football match on TV yesterday.

11. The children went home happily.

12. Your success depends on your self-confidence.

13. Her husband died of cancer.

14. On weekends, I go swimming.

15. I worked for two hours in my office yesterday.

\section{REFERENCES}

[1] Asma, T. (2010). Transfer of simple prepositions from standard Arabic into English: The case of third year LMD students of English language at Mentouri University-Constantine. Unpublished M.A. Thesis. Mentouri University-Constantine, Algeria.

[2] Brown, H. D. (2000). Principles of language learning and teaching ( $4^{\text {th }}$ ed.). San Francisco State University: Pearson Education Limited.

[3] Corder, S. P. (1971). Idiosyncratic dialects and error analysis. International Review of Applied Linguistics, 9, 147-159.

[4] Corder, S. P. (1973). Introducing applied linguistics. Middlesex: Penguin.

[5] Corder, S. P. (1974). The significance of learners' errors. In J. C. Richards (Ed.), Error analysis: Perspectives on second language acquisition (pp. 19-27). London: Longman.

[6] Corder, S. P. (1981). Error analysis and interlanguage. Hong Kong: Oxford University Press.

[7] Danesi, M. (2000). Semiotics in language education. Berlin: Mounton de Gruyter.

[8] Danesi, M. (2003). Second Language Teaching: A View from the Right Side of the Brain. The Netherlands: Kluwer Academic Publishers.

[9] Delshad, S. (1980). Persian and English prepositions compared and contrasted from a pedagogical point of view. Unpublished Doctoral Dissertation. University of Texas, USA.

[10] Erdogan, (2005). Contribution of error analysis to foreign language teaching. Mersin University Journal of the Faculty of Education, 1(2), 261-270.

[11] Gass, S. \& Selinker, L. (1994). Second language acquisition: An introductory course. Hillsdale: Lawrence Erlbaum Associates.

[12] Hamdallah, R, \& Tushyeh, H. (1993). A contrastive analysis of selected English and Arabic prepositions with pedagogical implications. Papers and Studies in Contrastive Linguistics, 28, 181-190.

[13] Hasan, A., \& Abdullah. I. (2009). The conceptual mapping of the English preposition into Arabic. European Journal of Social Sciences, 4(8), 604-613. 
[14] James, S. D. (1980). Contrastive analysis. London: Longman.

[15] Jimenez Catalan, R. M. (1996). Frequency and variability in errors in the use of English prepositions. Miscelanea, 17, 171-178.

[16] Kellerman, E, \& Smith, M. Sh. (Eds.) (1986). Cross-linguistic influence in second language acquisition. New York: Pergamon.

[17] Keshavarz, M. H.(1994). Contrastive analysis and error analysis. Tehran: Rahnama Press.

[18] Koosha, M. \& Jafarpour, A. A. (2006). Data-driven Learning and Teaching Collocation of Prepositions: The Case of Iranian EFL Adult Learners. Asian EFL Journal, 8(4), 192-209.

[19] Krzeszowski ,T. P.(1990). Contrasting languages: The scope of contrastive linguistics. Berlin: Mouton de Gruyter.

[20] Mahmoodzadeh, M. (2011). The Quest for Resolving Second Language Teaching Dilemma: A Review of the Proposed Solutions during the Last Two Decades. Theory and Practice in Language Studies, 1(10), 1375-1382.

[21] Nemster, W. (1971). Approximative systems of foreign language learners. International Review of Applied Linguistics, 9, 115123.

[22] Oller, J. W. \& Ziahosseiny, S. (1970). The contrastive analysis hypothesis and spelling errors. Language Leaning, 20, $183-189$.

[23] Pittman, G. A. (1966). Activating the use of prepositions. London: Longman.

[24] Quirk, R. et al. (1993). A University Grammar of English. London: Longman.

[25] Richards, J. C. \& Schmidt, R. (2002). Longman dictionary of language teaching and applied linguistics ( $3^{\text {rd }}$ Ed.). Malaysia: Pearson Education Limited.

[26] Russo, G. A. (1997). A conceptual fluency framework for the teaching of Italian as a second language. Unpublished Doctorial Dissertation. University of Toronto, Canada.

[27] Selinker, L. (1972). Interlanguage. International Review of Applied Linguistics, 10(3), 209-231.

[28] Stern, H. H. (1983). Fundamental concepts of language teaching. Oxford: Oxford University Press.

[29] Takahaski, G. (1969). Perceptions of space and function of certain English prepositions. Language Learning, 19, $217-234$.

[30] Talebinezhad, M. R. (2007). Conceptual fluency and metaphorical competence in second language acquisition: Two sides of the same coin? Journal of social Sciences and Humanities of Shiraz University, 26(4), 87-106.

[31] Talebinezhad, M. R. \& Hashemian, M. (2006). The development of conceptual fluency and metaphorical competence in L2 learners. Iranian Journal of Applied Linguistics, 9(1), 73-99.

[32] Wardhaugh, R. (1970). The contrastive analysis hypothesis. TESOL Quarterly, 4, 123-130.

[33] Whitman, R. \& Jackson, K. L. (1972). The unpredictability of contrastive analysis. Language learning, 22, 29-41.

[34] Wode, H. (1967). Developmental sequences in naturalistic L2 acquisition. Working Paper in Bilingualism, 11, 1-13.

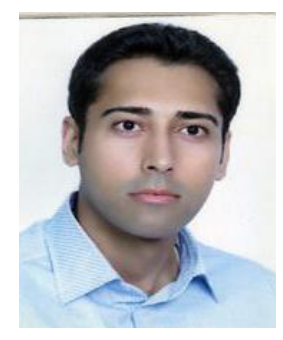

Masoud Mahmoodzadeh received his B.A. degree in English Language Translation from Imam Reza University (pbuh), Mashhad, Iran. He then got his M.A. degree in TEFL at Sheikhbahaee University, Isfahan. He has been teaching English to Iranian EFL learners at several language institutes for more than seven years. He has also taught General English courses at Sheikhbahaee University, Isfahan. As a researcher, he has contributed to some local and international journals such as Iranian EFL Journal, Theory and Practice in Language Studies, and Journal of Language Teaching and Research. His main areas of interest include second language acquisition, language teaching methodology, curriculum planning/evaluation, and the role of affective variables in language teaching. 